\title{
FEM Analysis of the Welding Seams Geometry in Case of Fillet Welds
}

\author{
Claudiu Babiș ${ }^{1}$, Andrei Dimitrescu ${ }^{1, *}$, Ana Maria Alecusan², and Marcela Babiș $^{3}$ \\ ${ }^{1}$ University Politehnica of Bucharest, Faculty of Industrial Engineering and Robotics, Bucharest, \\ Romania \\ ${ }^{2}$ Goethe German College, Bucharest, Romania \\ ${ }^{3}$ Secondary School no.1, Berceni, Romania
}

\begin{abstract}
The role of the welding seam is to achieve the non-removable joint between two or more parts. In principle, three geometric profiles of the welding seams can be obtained: straight profile; concave profile and convex profile. In practice, this geometric shape of the weld seam profile is very important, both in terms of the resistance of the joint to static stresses and in terms of its fatigue life. There are many factors that can influence the geometric shape of the weld seam: the welding process; welding regime; the nature of the filler materials used, the rehabilitation techniques applied and others. Often, this geometric shape of the weld bead is neglected, which is particularly dangerous due to the fact that an improper geometric shape can generate low mechanical strength in static loads or poor fatigue strength in variable loads. An optimum of the geometric configuration of the welding must be found, which reconciles both situations: the mechanical resistance in case of static stresses and also the fatigue resistance in case of variable loads. In this paper, an analysis will be made with finite elements for the straight and convex profile of the welding seams in the case of fillet welds subjected to fatigue. Several elements will be considered such as: damage; total deformation; fatigue sensitivity versus loading history; equivalent von Misses stress; safety factor.
\end{abstract}

\section{Introduction}

Welded constructions are loaded, both for fatigue and for static stresses. In the case of welded constructions in which there are fillet welded joints, stress concentrators make their presence felt in various ways. We can talk about internal stress concentrators, such as discontinuities (cracks, pores, inclusions) or external stress concentrators that can be introduced by the geometric shape of the welding seams or by the small connecting radii between the base material and the welded seam.

From the point of view of geometric configuration of the welding, the fillet welded joints can be made with straight, convex or concave welds. It is known that the largest stress concentrators are introduced by convex-shaped welding seams. Therefore, in the case of

\footnotetext{
${ }^{*}$ Corresponding author: claudiubbs@gmail.com
} 
welded joints, we must take into account these stress concentrators and investigate how they influence the failure of welded structures, for static and fatigue loads.

It is known that in the case of fillet welded joints loaded with variable loads, sometimes a great effort is made to reduce the stress concentrators. In this sense, several reconditioning technologies are known, such as the "Grinding weld toe" and the "WIG remelting weld toe" technology [1],[2],[3],[4],[5]. In both cases, the aim is to reduce the stress concentrators by increasing the radius between the weld and the base plate, in the first case by milling the intersection between the base material and the seam and in the second case by melting its WIG. The application of the two techniques is equivalent to the transformation of the convex shape welds into straight shape welds.

Our own research has shown that for thicknesses over $8 \mathrm{~mm}$ of the weld seams, the application of these techniques to reduce the stress concentrators is justified for fillet welded joints loaded for fatigue, obtaining an important increase in fatigue life [6], [7],[8]. Instead, the application of these techniques has no influence on the failures of the statically loaded fillet welded joints. In this sense, it is necessary to investigate the influence of stress concentrators on variable loaded, for the fillet welded joints that have the seam thicknesses below $5 \mathrm{~mm}$.

\section{Experiment description}

This paper analyzes the influence of the geometric configuration of the welding with thicknesses less than $5 \mathrm{~mm}$, for the fillet welded joints. Only the case of fatigue loaded joints is analyzed because it is expected that for the static load joints, it will not influence the failures. The straight and convex configuration of the bead is studied.

For the FEM analysis, we start from the following data: the welded joint is cruciform and has fillet welds, the thickness of the weld seam is less or equal to $5 \mathrm{~mm}$, for the variable load it is considered the traction and compression force of $+-5 \mathrm{KN}$, symmetric alternating cycle load, frequency $10 \mathrm{~Hz}$. The base material thickness is $10 \mathrm{~mm}$. The plate material is a construction steel, type S $235 \mathrm{JR}$. The basic characteristics of fatigue stress are presented in table 1 .

Table 1. The basic characteristics

\begin{tabular}{|c|c|}
\hline Characteristic & Value \\
\hline Base material & S235JR \\
\hline $\begin{array}{c}\text { Thickness of the base material } \\
{[\mathrm{mm}]}\end{array}$ & 10 \\
\hline $\begin{array}{c}\text { Type of welded joint } \\
{[\mathrm{mm}]}\end{array}$ & \begin{tabular}{c} 
Cruciform fillet welded joint \\
\hline $\begin{array}{c}\text { Thickness of the weld seam a } \\
\text { Geometric shape of the weld }\end{array}$ \\
\hline Fatigue load
\end{tabular} \\
\hline $\begin{array}{c}\text { Straight and convex } \\
\pm 5 \mathrm{KN}\end{array}$ \\
\hline Frequency of the load $\mathrm{f}[\mathrm{Hz}]$ & 10 \\
\hline
\end{tabular}

After the application of the loads, a certain value of the total displacements and of the Von Misses tensions will result. Several aspects will be researched which will be briefly described below. Von Mises stress is a value of stress, used to determine if a given material 
will yield or fracture. The Von Mises yield criterion states that if the von Mises stress of a material under load is equal or greater than the yield limit of the same material under simple tension, then the material will yield [9].

Fatigue life is the available life for a given fatigue analysis. This fatigue life could refer to the whole model or only of some parts, surfaces, edges, etc. If loading is constant in amplitude, fatigue life represents the number of cycles until the part will fail to fatigue. But if the loading is non-constant, fatigue life represents the number of loading blocks until failure [9].

Fatigue damage is defined as the design life/available life. The default design life can be set manually. For fatigue damage, values greater than 1 , will indicate failure before the design life is reached [9].

Fatigue safety factor represent a factor of safety refer to fatigue failure at a given design life. The maximum fatigue safety factor is 15 . For fatigue safety factor less than one indicate, the failure before the design life is reached [9].

Fatigue sensitivity shows how the fatigue results change as a function of the loading at the critical location on the model. Sensitivity may be found for life, damage, or factor of safety [9].

Biaxiality indication gives information about the stress state over the model and how to interpret the results. Biaxiality indication is defined as the principal stress smaller in magnitude, divided by the larger principal stress with the principal stress nearest zero ignored. A biaxiality of zero corresponds to uniaxial stress, a value of -1 corresponds to pure shear, and a value of 1 correspond to a pure biaxial state [9].

\section{FEM analysis for fillet welds with straight geometric shape}

The total deformation resulting from the load is presented in figure 1a. This varies between zero and the maximum value of $0.027 \mathrm{~mm}$. It is observed that in the case of the seam with a straight geometric shape, the maximum deformation is achieved at the upper part of the test sample and not in the area of the welding seam.

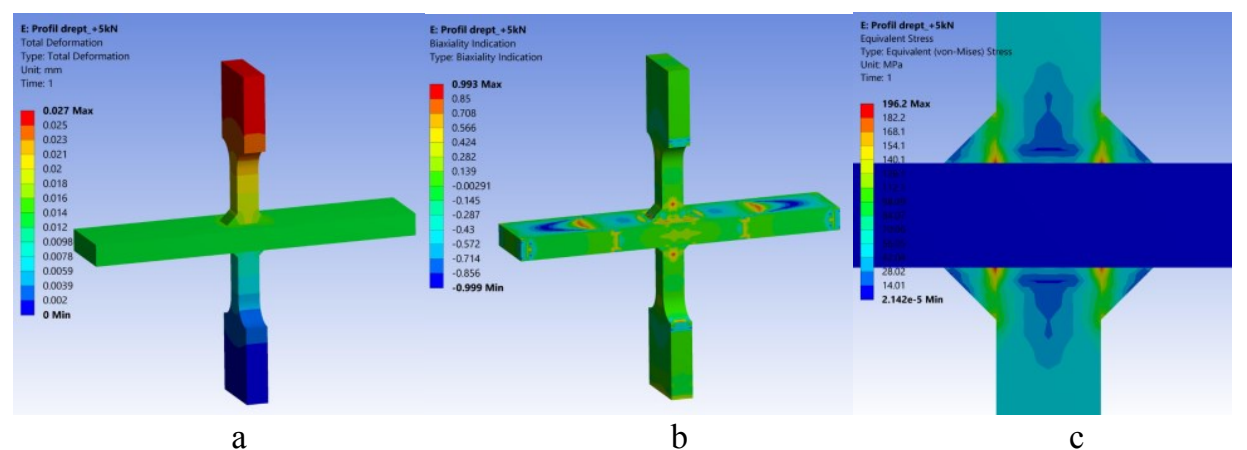

Fig.1. Total deformation for the tensile stress, in case of the straight fillet welds: a- deformation; bbiaxiality indicator; c- the Von Misses stress level.

Figure $1 \mathrm{~b}$ shows the biaxiality indicator for the straight profile and its variation in different areas of the welded joint. It is observed that the biaxiality indicator is between a minimum value of -0.999 and a maximum one, of +0.993 . 
The stress level of Von Misses is shown in figure 1c. It is observed that for the straight seam, they vary between the minimum value of $2.242 * 10^{-5} \mathrm{MPa}$ and the maximum of 196.2 $\mathrm{MPa}$. The maximum value is found in the root zone of the weld seam.

\section{FEM analysis for fillet welds with convex geometric shape}

The total deformation resulting from the load is presented in figure $2 \mathrm{a}$. This varies between zero and the maximum value of $0.027 \mathrm{~mm}$. It is observed that the maximum deformation in this case too, is made at the upper part of the test sample and not in the area of the welding seam.

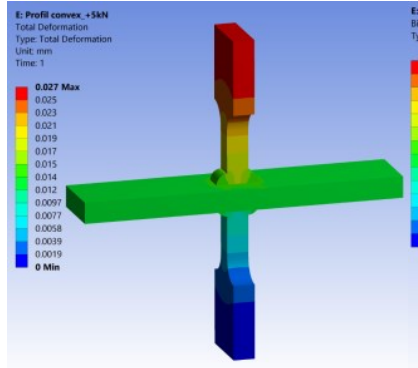

a

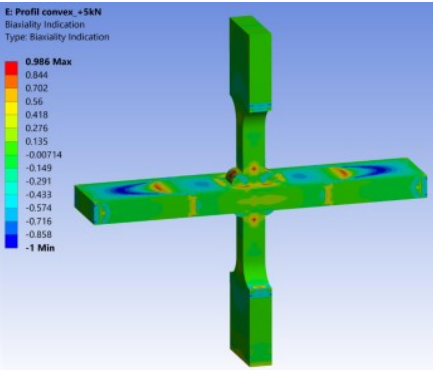

b

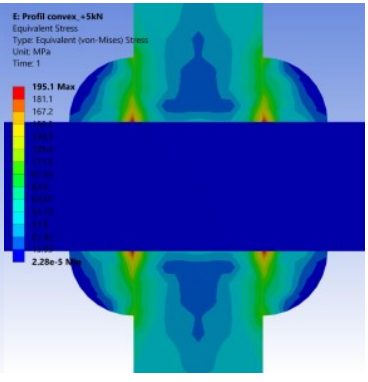

c

Fig.2 Total deformation following tensile stress for the convex fillet welds profile.

Figure $2 \mathrm{~b}$ shows the biaxiality indicator for the convex profile. It is observed that it is between a minimum value of -1 and a maximum one of +0.986 . There is an increase in the maximum value of the biaxiality indicator from the maximum value of 0.986 for the case of the convex profile to the maximum value of 0.993 for the case of the straight profile.

The Von Misses stress level is shown in figure 2c. It is observed that for the convex welds, they vary between the minimum value of $2,280 * 10^{-5} \mathrm{MPa}$ and the maximum of $195.1 \mathrm{MPa}$. The maximum value is found in the root zone of the weld seam.

\section{Results}

After the application of the loads, the damages were obtained for the straight and convex fillet welds, which are shown in figure 3 . It is found that the damages are approximately similar and are not too much influenced by the geometric shape of the welding seams.

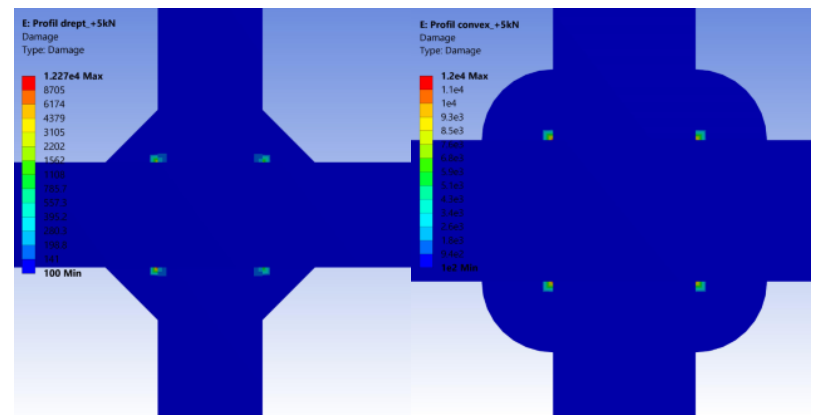

Fig. 3. The damages for the straight and the convex fillet welds.

It is observed that the potential damage areas are at the root of the weld seam. The values of the damage are between the minimum value of 100 and the maximum value of $1,227 * 10^{4}$ 
for the stright welds. For the convex welds a minimum value of 100 and a maximum value of $1.2 * 10^{4}$ were recorded. It is observed that the maximum values are relatively close. Regarding the variation of failures according to the fatigue loading history, they are presented in figures 4 and 5, both for straight and convex welds.

The fatigue life variation graph for the stright fillet welds is shown in figure 4 .

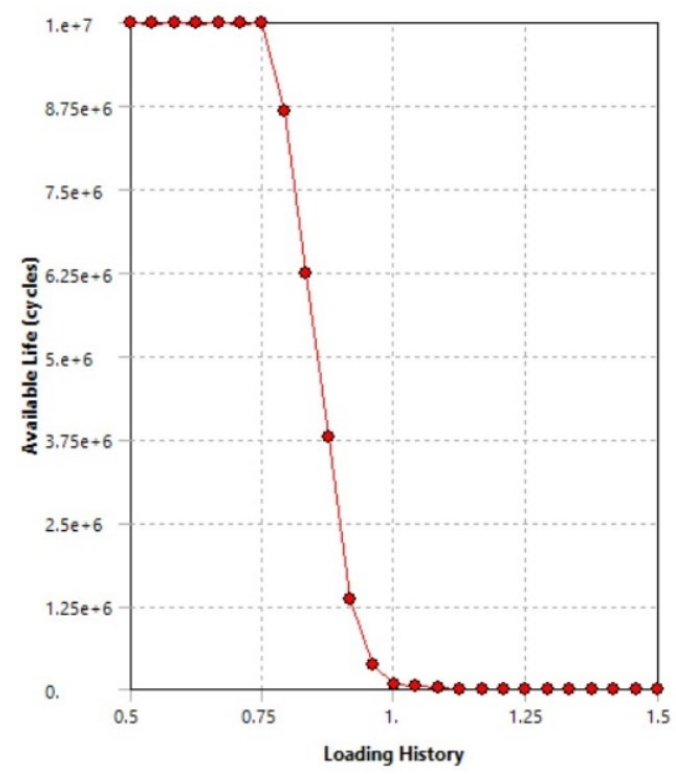

Fig. 4. The fatigue life for the straight fillet welds.

The fatigue life cycle variation graph for the convex fillet welds is shown in figure 5 .

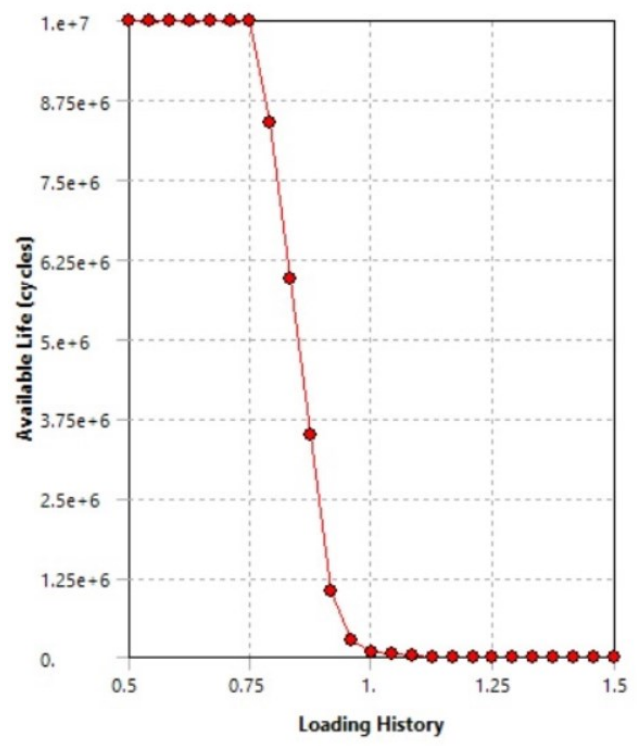

Fig. 5. The fatigue life for the convex fillet welds.

Figure 6 shows the Security Factor for the two types of fillet welds, straight and convex. 


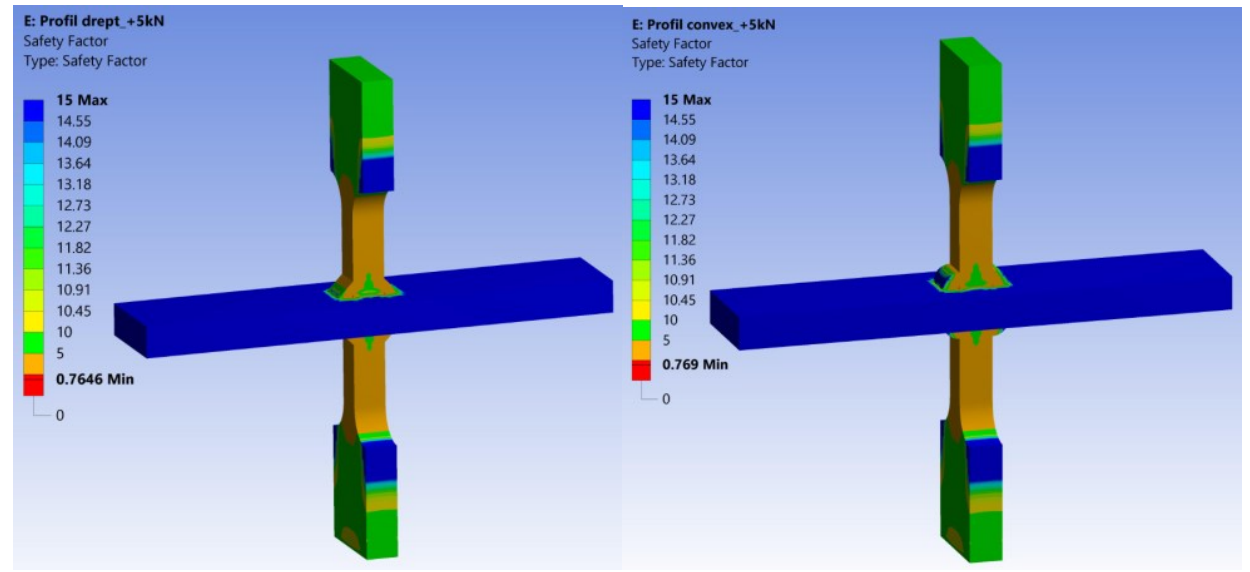

Fig. 6. The Safety Factor for the two types of fillet welds, straight and convex.

It is observed that in both cases, that the Safety Factor varies between a minimum value of 0.7646 for the straight welds, respectively 0.769 for the convex welds and the maximum value of 15 , in both cases.

Following the FEM analysis, the following interpretations which are presented below, can be drawn.

From the point of view of the total deformations appeared after the loads (figures 1a and 2a) it was found that both cases of welded joints with straight or convex profile, behave similarly. It was observed that in both cases there was a maximum displacement of $0.027 \mathrm{~mm}$ in the force actuation area, ie at one of the ends of the sample. In both cases, in the area of the welding seams, a small deformation was registered, of approximately $0.014 \mathrm{~mm}$. This deformation places us in the area of elastic deformations.

The biaxiality indicator gives us indications on the stress state of the entire welded joint (figures $1 \mathrm{~b}$ and $2 \mathrm{~b}$ ). The highest values close to 1 of the biaxiality indicator are found at the intersection between the welding seam and the base material. There is a maximum value of 0.993 for the welded joint with straight welds and 0.986 for the welded joint with convex welds. In these areas, because the biaxiality indicator is close to the value 1 , we can say that we have a biaxial state of tension. It is found that in the rest, in both cases, values of the biaxiality indicator approximately equal to 0 predominate, which indicates a monoaxial state of stresses.

Von Mises stress is a value of stress, used to determine if a given material will yield or fracture. The Von Mises yield criterion states that if the von Mises stress of a material under load is equal or greater than the yield limit of the same material under simple tension, then the material will yield [9]. In both cases of straight or convex fillet welded joints, being totally non-penetrated welds, the highest values of von Mises stresses were obtained at the root of the weld bead, at the intersection between the two sheets (figures 1c and 2c). For the welded joint with straight welds, the maximum value of 196.2 MPa was obtained and for the welded joint with convex welds, the value of $195.1 \mathrm{MPa}$ was obtained. Both von Mises stress values are lower than the yield strength of the base material, which is $235 \mathrm{MPa}$. Therefore, in both cases, in the area of maximum von Mises stresses, failure by fracture will eventually occur. In that area we will not have plastic deformation.

From the damage analysis, the same thing was found, namely that the predictable failure areas are those at the root of the weld seams, at the intersection between the two sheets of the welded joint (figure 3). Similar values were obtained for failure, for both geometries of the welding seams. For straight welds the value of $1.227 \mathrm{e} 4$ was obtained and for convex welds, the value of $1.2 \mathrm{e} 4$. 
In terms of fatigue life depending on the loading history, similar values were found for both weld seam geometries (Figures 4 and 5). In both cases it is found that as the load increases, the fatigue life decreases. It is found that the minimum number of fatigue life cycles is 1548 for fillet welded joint with straight welds and 1312 for fillet welded joint with convex welds. There is a slight decrease in the number of the fatigue life cycles in case of the fillet welded joint with convex welds, compared to the other with straight welds.

Regarding the safety factor, it can be seen from figure 6 that it varies between a minimum value of 0.7646 for the fillet welded joint with straight welds, respectively 0.769 for the fillet welded joint with convex welds and the maximum value of 15 , for both cases. It is observed that for both welded joints, the areas with a safety factor of 15 , ie the safest, are the areas outside the welding seams, especially in the horizontal plate. It can be seen that the most insecure areas with the lowest values of the safety factor are at the intersection between the welding seams and the base material.

\section{Conclusions}

They were analyzed from the point of view of the fatigue stress and tensile - compression stress cycle of $\pm 5 \mathrm{kN}$, two cruciform fillet welded joints, with the weld seam thickness of 5 $\mathrm{mm}$, one having straight shape and the other convex shape weld seams. It was wanted to investigate the differences in the fatigue behavior of the two joints, taking into account the geometric shapes of the welding seams. Given that the rehabilitation techniques Grinding weld toe and WIG remelting weld toe, referred to in the introduction, is equivalent to transforming the convex welds into the straight ones, we can say that this paper actually investigates whether the use of the two techniques is justifies being applied for thicknesses welds, less than or equal to $5 \mathrm{~mm}$.

As a conclusion, it can be appreciated that the fillet welded joints, with a thickness of the fillet welds equal to or less than $5 \mathrm{~mm}$, both in the case of seams with straight geometry and in the case of those with convex geometry, behave similarly in case of the fatigue loads. However, there is a decrease in the number of life cycles in the case of fillet welded joints with convex seams, compared to those with straight seams.

Therefore, the application of rehabilitation techniques by which the welding seams with convex geometry are transformed into welding seams with flat geometry, is justified to be done in the case of welds with cord thicknesses less than or equal to $5 \mathrm{~mm}$, but only after an judicious analysis.

\section{References}

1. O. Chivu, C. Babis, A. Semenescu, O.D. Negoita, G. Iacobescu, A. Dimitrescu, Sustainab.M.D.P.I. 10, 18 (2018)

2. G. Amza, C. Babis, D. Nitoi, Metalurg. 53, 4 (2014)

3. C. Babis, A. Dimitrescu, O. Chivu, A. Semenescu, V. Petrescu, Mat.Sc. and Eng. 200, 6 (2018)

4. 4.M. Braun, X, Wang, International Journal of fatigue, 145(2021)

5. 5. T. Shiozaki, N. Yamguchi, Y. Tamai. J. Hiramoto. K. Ogawa, International Journal of fatigue, $116(2018)$

6. C. Babis, O. Chivu, D. Dobrota, Metalurg. 53, 3 (2014)

7. C. Babis, A. Dimitrescu, O. Chivu, A. Semenescu, V. Petrescu, Mat.Sc. and Eng. 400, 7 (2018)

8. H. Rohani Raftar, M. Dabri, AAhola, T. Bjork, International Journal of fatigue, 114 (2021)

9. More Sri Vidhya, K. V. Merlyn Christina, International Research Journal of Engineering and Tehnology, 07, 09 (2020) 